\title{
An examination of the impact of Olson's Extinction on tetrapods from Texas
}

\author{
Neil Brocklehurst ${ }^{\text {Corresp. } 1}$ \\ ${ }^{1}$ Museum für Naturkunde, Leibniz-Institut für Evolutions- und Biodiversitätsforschung, Berlin, Germany \\ Corresponding Author: Neil Brocklehurst \\ Email address: neil.brocklehurst@mfn-berlin.de
}

It has been suggested that a transition between a pelycosaurian-grade synapsid dominated fauna of the Cisuralian (early Permian) and the therapsid dominated fauna of the Guadalupian (middle Permian), was accompanied by, and possibly driven by, a mass extinction dubbed Olson's Extinction. However, this interpretation of the record has recently been criticised as being a result of inappropriate time-binning strategies:

calculating species richness within international stages or substages combines extinctions occurring throughout the late Kungurian stage into a single event. To address this criticism, I examine the best record available for the time of the extinction, the tetrapodbearing formations of Texas, at a finer stratigraphic scale than those previously employed. Species richness is calculated using four different time-binning schemes: the traditional Land Vertebrate Faunachrons (LVFs); a re-definition of the LVFs using constrained cluster analysis; individual formations treated as time bins; and a stochastic approach assigning specimens to half-million-year bins. Diversity is calculated at the genus and species level, both with and without subsampling, and extinction rates are also inferred. Under all timebinning schemes, both at the genus and species level, a substantial drop in diversity occurs during the Redtankian LVF. Extinction rates are raised above background rates throughout this time, but the biggest peak occurs in the Choza Formation (uppermost Redtankian), coinciding with the disappearance from the fossil record of several of amphibian clades. This study, carried out at a finer stratigraphic scale than previous examinations, indicates that Olson's Extinction is not an artefact of the method used to bin data by time in previous analyses. 


\section{An Examination of the Impact of Olson's Extinction on Tetrapods from Texas}

2

3 Neil Brocklehurst ${ }^{\mathrm{a}}$

4

a Museum für Naturkunde, Leibniz-Institut für Evolutions- und Biodiversitätsforschung,

8 Corresponding Author: Neil Brocklehurst, neil.brocklehurst@mfn-berlin.de, +493020938306 


\section{Abstract}

25 It has been suggested that a transition between a pelycosaurian-grade synapsid dominated fauna

26 of the Cisuralian (early Permian) and the therapsid dominated fauna of the Guadalupian (middle

27 Permian), was accompanied by, and possibly driven by, a mass extinction dubbed Olson's

28 Extinction. However, this interpretation of the record has recently been criticised as being a

29 result of inappropriate time-binning strategies: calculating species richness within international

30 stages or substages combines extinctions occurring throughout the late Kungurian stage into a

31 single event. To address this criticism, I examine the best record available for the time of the

32 extinction, the tetrapod-bearing formations of Texas, at a finer stratigraphic scale than those

33 previously employed. Species richness is calculated using four different time-binning schemes:

34 the traditional Land Vertebrate Faunachrons (LVFs); a re-definition of the LVFs using

35 constrained cluster analysis; individual formations treated as time bins; and a stochastic approach

36 assigning specimens to half-million-year bins. Diversity is calculated at the genus and species

37 level, both with and without subsampling, and extinction rates are also inferred. Under all time-

38 binning schemes, both at the genus and species level, a substantial drop in diversity occurs

39 during the Redtankian LVF. Extinction rates are raised above background rates throughout this

40 time, but the biggest peak occurs in the Choza Formation (uppermost Redtankian), coinciding

41 with the disappearance from the fossil record of several of amphibian clades. This study, carried

42 out at a finer stratigraphic scale than previous examinations, indicates that Olson's Extinction is

43 not an artefact of the method used to bin data by time in previous analyses. 


\section{Introduction}

A faunal turnover of tetrapods has long been recognised between the Cisuralian and

50 Guadalupian (early and middle Permian, respectively). The former is characterised by a diverse

51 array of amphibians, pelycosaurian-grade synapsids (particularly carnivorous sphenacodontids

52 and herbivorous edaphosaurids), and captorhinids, whereas the latter is dominated by therapsid

53 synapsids, with increased diversity of parareptiles and amphibian diversity substantially reduced

54 (Olson 1962, 1966; Kemp 2005; Sahney \& Benton 2008; Ruta et al. 2011; Benton 2012; Benson

55 et al. 2013; Brocklehurst et al. 2013; 2017). These faunal changes were accompanied by

56 ecological shifts, including a transition towards more complex ecosystems with abundant large

57 tetrapods as primary consumers (Olson 1966). However, the nature and progress of the transition 58 is still strongly debated.

59 The possibility of a mass extinction accompanying this transition was first suggested by

60 Olson (1982), who noted a drop in the number of families across Cisuralian/Guadalupian

61 boundary. This drop was principally concentrated among amphibian families (amniote diversity

62 was shown to increase slightly). Sahney \& Benton (2008) provided a more detailed examination

63 of diversity through the Permian, still at the family level but with temporal resolution at the stage

64 level. Decreases in both species richness, diversification rate and ecological diversity were

65 apparent through the Kungurian and Roadian (the last stage of the Cisuralian and the first of the

66 Guadalupian respectively). Sahney \& Benton (2008) dubbed this mass extinction event “Olson's

67 Extinction" and hypothesised that it might have been a causal factor in the faunal turnover

68 occurring at this time. 
The hypothesis of Sahney \& Benton has been criticised as being based on family-level data that was not corrected for sampling heterogeneity (Benson \& Upchurch 2013, Brocklehurst et al. 2013). Nevertheless, subsequent studies both of tetrapods as a whole (Benton 2012, Benton et al. 2013, Benson \& Upchurch 2013, Brocklehurst et al. 2017) and subgroups within Tetrapoda (Ruta \& Benton 2008, Ruta et al. 2011, Brocklehurst et al. 2013, 2015), carried out at species and genus levels and employing a variety of sampling correction methods, have identified diversity decreases across the Kungurian/Roadian boundary.

Despite this, the theory of Olson's Extinction has been criticised in other ways. Benson \& Upchurch (2013) suggested that the mass extinction was an artefact of the geographically patchy fossil record. The record from the Cisuralian is known almost entirely from palaeoequatorial localities, particularly from North America and Europe, whereas that of the Guadalupian is dominated by palaeotemperate localities from Russia and South Africa (Lucas 2004, Kemp 2006). Not only does this make it difficult to ascertain over what timescale the extinction took place and to what extent the transition was a global event, but the apparent diversity drop might simply represent a latitudinal diversity gradient (Benson \& Upchurch 2013). In most modern clades, diversity is higher in equatorial regions than temperate regions (Willig et al. 2003, Hildebrand 2004), and so it was argued that the shift in sampling locality from more diverse to less diverse latitudes might be the cause of the apparent decrease in species richness (Benson \& Upchurch 2013). Brocklehurst et al. (2017), however, argued against this point of view. It has been noted that the latitudinal diversity gradient was not a constant feature through geological time (Archibald et al. 2010, Rose et al. 2011, Yasuhara et al. 2012, Mannion et al. 2012, 2014), and it was demonstrated that, in the few Permian time bins where tetrapod data was available 
91 from both palaeoequatorial and palaeotemperate latitudes, the temperate latitudes exhibited

92 higher species richness after correcting for sampling (Brocklehurst et al. 2017).

Further criticism of Olson's Extinction was put forward by Lucas (2017a). Lucas argued

that the inference of a mass extinction across the Kungurian/Roadian at this time was an artefact

of two confounding factors. First, the majority of the studies cited used geological stage or

substages as their time bins, thus conflating extinctions occurring throughout the Kungurian into

97 a single event.

Second, Lucas (2017a) argued that incorrect ages were applied to numerous geological

formations, in particular the San Angelo and Chickasha formations of Texas and Oklahoma,

respectively. The ages of these formations have long been a point of contention. Early estimates

101 placed them in the latest Leonardian (late Kungurian) (Lucas \& Heckert 2001, Lucas 2004), but

102 discovery of a specimen, from Chickasha, of the parareptile Macroleter, previously only known

103 from the Middle Permian of Russia, caused Reisz \& Laurin (2001) to argue for an equivalency

104 between this formation and the Kazanian-aged (earliest Guadalupian) faunas of Russia. Lucas

105 (2002) rejected their arguments based on the ammonite fauna of the Blaine Formation, a marine

106 formation immediately overlying the San Angelo, which he claimed supported a Leonardian age.

107 Reisz \& Laurin (2002) criticised the interpretation of Lucas, suggesting that a key taxon in the

108 arguments had a much longer range than suggested and highlighting previous studies of the

109 Blaine formation interpreting it as Guadalupian in age. Lozovsky (2003) also used ammonite

110 biostratigraphy to support a Roadian age for the Chickasha and San Angelo formations, and

111 these ages have been adopted in most subsequent studies (e.g. Sahney \& Benton 2008, Benton

112 2012, Brocklehurst et al. 2013, 2017). However, Lucas (2017a) still supports a latest Kungurian

113 age for these two formations. He therefore suggested that an extinction across the 
114 Kungurian/Roadian boundary cannot be assessed in a global framework, as there is no

115 stratigraphic overlap between the North American and Russian formations.

116 It is not the purpose of this paper to argue against these two criticisms of Lucas (2017a).

117 Indeed, I am fully prepared to agree that time-binning strategies employing the geological stages

118 or substages, while often necessary for global analyses where the correlations between the

119 regional biostratigraphic schemes are inexact, have the potential to produce spurious results.

120 Such binning strategies produce time-averaged diversity estimates for a time bin that can differ

121 from the true standing diversity at any one time in the bin (Raup 1972, Lucas 1994, Foote 1994,

122 Miller \& Foote 1996, Alroy 2010a, Gibert \& Escarguel 2017). Instead it is my intention to

123 approach the question of Olson's extinction from a different angle, one that addresses the issues

124 of binning strategy while bypassing the disagreements surrounding the ages of the San Angelo

125 and Chickasha formations. In fact, the framework of this analysis is one suggested by Lucas

126 himself (Lucas 2017a): when the fossil record is geographically patchy with uncertain global

127 correlations, it is better to study mass extinctions using the "best sections" method, focussing one

128 or a few well sampled, stratigraphically dense fossiliferous sections to examine the progress of

129 the extinction. While only providing a local perspective on the event under study, this method

130 does allow more detailed analysis than is provided in global studies with coarse temporal

131 resolution.

132 The "best section" of tetrapods in the Cisuralian is doubtless that of Texas, which

133 represents a reasonably continuous sequence from the late Carboniferous until the end of the

134 Cisuralian (Romer 1928, 1935, Hook 1989, Lucas 2006, 2017a). A detailed examination of the

135 Cisuralian tetrapod record from Texas, covering the stratigraphic sequence from the Pueblo

136 Formation until the San Angelo Formation, allows much higher resolution than previous studies. 
137 Moreover, it renders the debate regarding the age of the San Angelo formation moot. The issue is

138 no longer whether there is a Kungurian/Roadian boundary event, but instead whether an

139 extinction event is identified between the Redtankian and Littlecrotonian land vertebrate

140 faunachrons (biostratigraphic time bins based on the tetrapod fossil record, the former correlating

141 in Texas with the Clear Fork Group, the latter with the San Angelo Formation). The presence of

142 an extinction event between these two faunachrons is assessed at both genus and species levels,

143 with four different time-binning systems and results shown both with and without sampling

144 correction.

145

146 Materials and Methods

147 Data

148 Data on the number of specimens of tetrapod species in each time bin was assembled

149 from a variety of sources. The primary literature and the paleobiology database, downloaded

150 from the fossilworks website (http://fossilworks.org) on October 2017, were the principal

151 sources, but were supplemented by observation of specimens in museum collections and also by

152 data sent from some museums (Museum of Comparative Zoology, Harvard; Field Museum of

153 Natural History, Chicago; American Museum of Natural History, New York; Yale Peabody

154 Museum, New Haven; University of California Museum of Palaeontology, Berkeley; Sam Noble

155 Oklahoma Museum of Natural History, Norman). Specimens of uncertain provenance were not

156 included. The data was examined at both species and genus level. While it has often been the

157 preference to examine data at the species-level (Sepkoski [1984] argued that as the species are

158 the real "units" of evolution, it is at that level that evolution should be studied), Lucas (2017a)

159 suggested that the genus is preferable for early Permian tetrapods to avoid the influence of large 
160 numbers of singletons (single-specimen taxa), which under poor sampling produce a great deal

161 of "noise" in the evolutionary signal (Alroy 1998, Foote 2000). The data does not include a large

162 number of species represented by only a single specimen (18 out of 102), but more than half (65)

163 the taxa represent single-occurrences (present in only one formation). The final datasets are 164 provided in Data S1 and S2.

165

166

Time bins

167 Four methods were used to define time bins, each successively dividing the early Permian

168 into smaller portions of time. The first set of bins used are the land vertebrate faunachrons

169 (LVFs): the biostratigraphic bins based on the first and last appearances of key tetrapod genera

170 (Lucas 1998). As these are biostratigraphic bins, their boundaries should correspond to major

171 periods of turnover among tetrapods, and so the diversity estimates within each faunachron

172 should provide a better approximation of the standing diversity at any point in time than using

173 the international stages. In fact, since the boundaries of the Cisuralian LVFs are primarily based

174 on the section under study, they are more likely to coincide with events relevant to the taxa under 175 study.

176 The second binning scheme used represents a redefinition of the land vertebrate

177 faunochrons using a clustering approach. CONISS is a constrained clustering analysis, which

178 groups stratigraphic sections into hierarchical clusters based on the taxonomic distances between,

179 while maintaining the order of the stratigraphic sequence (Grimm 1987). The taxonomic

180 distances between the formations were calculated using Alroy (2015a)'s modification of the

181 Forbes metric, applying the RAC correction suggested by Brocklehurst et al. (2018a) to account

182 for differences in the evenness of the relative abundance distributions, which under incomplete 
183 sampling can bias the distances observed. The functions to carry out the RAC method are

184 available on Dryad (Brocklehurst et al 2018b) on Dryad. The CONISS analysis was carried out

185 in $\mathrm{R}$ version 3.3.2 ( $\mathrm{R}$ core team 2016), using functions from the package rioja (Juggins 2009).

186 The boundaries of the original LVFs were then shifted to ensure that formations which were

187 clustered together were grouped in the same bin.

188 The third binning scheme simply treats each formation as a time bin. The

189 lithostratigraphy was devised by Plummer \& Moore (1921) and dated based on the marine strata

190 which intercalate with the terrestrial strata. This provides a finer resolution than the land

191 vertebrate faunachrons (11 bins rather than 5) and later refinements of the lithostraigraphy (e.g.

192 Hentz 1988).

193 The fourth and final binning scheme uses a stochastic approach, in an attempt to address

194 the time averaging that occurs when coarse time bins covering several million years are

195 employed. The ages of the top and bottom of each formation were used as maximum and

196 minimum bounds on the ages of each specimen known from within that formation. The period of

197 time under study was split into half-million-year time bins, and each specimen was assigned at

198 random to one of the bins between its maximum and minimum age brackets. 100 such datasets

199 were generated, and the analyses of diversity and extinction rate were applied to all 100 . Such

200 stochastic methods have been shown to provide more accurate estimates of standing diversity

201 than binning approaches, even when the origination and extinction are biased towards coinciding

202 with the boundaries of bins (Gibert \& Escarguel 2017).

203 For all four binning schemes, the absolute ages were derived from Lucas (2017a, b),

204 using his correlations of the formations to the international stages. Thus, the Littlecrotonian LVF

205 and the San Angelo formation are deemed to be latest Kungurian rather than Roadian. For most 
206 of the binning schemes, this does not make a difference; when analysing only the Texas "best

207 section", the question of whether an extinction event is identified between the Redtankian and

208 Littlecrotonian is more relevant than the precise timing of the boundary. Where the absolute ages

209 do make a difference is in calculating extinction rates using the stochastic binning scheme. By

210 compressing the Redtankian and Littlecrotonian into a smaller period of time, the density of the

211 specimens sampled is increased. This will lower extinction rates estimated under the gap-fillers

212 method (see below): counts of two-timers will increase and counts of part-timers and gap-fillers

213 will decrease (terminology from Alroy 2014). The use of a Kungurian age for the Littlecrotonian

214 is therefore more conservative, biasing against the inference of a mass extinction.

215

216 Diversity and Rate Estimates

217 For each time bin in each binning scheme, diversity (species richness) estimates were

218 calculated using two methods. The first is a taxic diversity estimate, a simple count of the

219 number of species observed in each time bin without sampling correction. The second employs

220 shareholder quorum subsampling (SQS; Alroy 2010), which standardises the coverage (the

221 proportion of the rank abundance distribution sampled) in each time bin, and has been shown by

222 both simulation studies and empirical data to be a robust method of correcting for preservation

223 and sampling heterogeneity (Alroy 2010; Chao and Jost 2012; Close et al. 2018). Coverage is

224 measured using Good's U (the proportion of singletons relative to the total sample size).

225 Diversity was estimates at four levels of coverage: 0.6-0.9 at intervals of 0.1 (a quorum of 0.6

226 allowed diversity to be calculated in all time bins in all binning schemes). SQS diversity

227 estimates were calculated in R using version 3.3 of the function available on the website of John

228 Alroy (http://bio.mq.edu.au/ jalroy/SQS.html). The stochastic binning method allows the 
229 implementation of the more precise and accurate methods of calculating extinction rates using

230 the gap fillers method (Alroy 2014). Since this method is based on estimating sampling from the

231 patterns of occurrences in a moving "window" covering four time bins, it is impractical to apply

232 it to the short time series produced by the three other binning strategies. The gap-fillers method

233 was implemented, applying the "two for one" correction (Alroy 2015b) to increase precision,

234 using custom functions written in R. As suggested by Alroy (2014), sampling heterogeneity was

235 accounted for by classical rarefaction (standardising the sample size by number of occurrences)

236 rather than by standardising coverage. 10000 subsampling iterations were carried out, each

237 drawing five occurrences per time bin. Origination rates were calculated using the same

238 equations; the methods used to calculate sampling apply equally well in reverse (Alroy 2014).

239 This was carried out using custom code, provided in Data S3.

241 Results

242 Redefined Land Vertebrate Faunachrons

243 When clustering the formations using CONISS, a number of changes are made to the

244 boundaries of the LVFs (Fig. 1). The Littlecrotonian and Redtankian remain as they were defined

245 previously. The lower boundary of the Mitchellcreekian is shifted downwards to include the

246 Belle Plains Formation, found to cluster more closely with the Clyde than the Admiral

247 Formation. The Admiral Formation itself clusters with the Putnam Formation, and so the

248 Seymourian LVF is redefined to include these two. Thus, the Coyotean LVF contains only the 249 Pueblo and Moran formations.

250 It is worth clarifying here that this analysis is not intended to cast doubt on the LVFs as

251 originally defined; rather they represent a biostratigraphic scheme more specific to the Texas 
252 section. The changes to the Coyotean LVF are most likely due to this being primarily defined by

253 taxa from the well sampled early Cisuralian localities in New Mexico (Lucas 1998, 2017b),

254 which are not included in this study.

255

256

Diversity estimates

257

Raw, uncorrected species and genus-level diversity estimates indicate a substantial fall in 258 diversity between the Redtankian and Littlecrotonian, based on all four time-binning schemes

(Fig. 2). The finer resolution time bins (formation-level and half-million-year time bins) indicate that the Arroyo Formation represents the peak richness, and number of genera and species

261 declined throughout the Redtankian.

262 When the data are binned by the Land Vertebrate Faunachrons (whether original or 263 redefined), subsampling by SQS supports the Littlecrotonian as the time of lowest diversity

264 (Figs. 3-4). The status of the Redtankian as a diversity peak is less clear; when the original LVFs

265 are used, the Mitchellcreekian is found to contain a similar richness to the Redtankian (Fig. 3).

266 However, the redefined LVFs indicate a substantial increase between these two bins (Fig. 4).

267 The higher-resolution-binning schemes both indicate the drop in subsampled diversity

268 occurs throughout the Redtankain (Figs. 5-6). The Arroyo formation produced the highest

269 species and genus richness of this faunachron, and the diversity deceases in the Vale Formation 270 and reaches a trough in the Choza formation. When subsampling is applied, species and genus

271 richness is found to increase slightly between the Choza and San Angelo formations. 272

273 Extinction and Origination rates 
275 the top of the Belle Plains, Arroyo and Choza formations (the latter being the largest) (Fig. 7).

276 During the time covered by the Vale Formation, extinction rates fall, but remain above

277 background levels. The principal difference between the species and genus curves is the relative

278 height of the Belle Plains extinction peak; at the species level it is higher than the Arroyo peak.

279 Peaks in origination rates at the species level are observed at the bottom of the Arroyo

280 and the San Angelo formations (Fig. 8). The former of these peaks is not observed at the genus

281 level, although the latter is still prominent.

282

283 Discussion

284 Having argued against an extinction of tetrapods across the Kungurian/Roadian boundary

285 (due to the inappropriate time-binning strategies used in other diversity studies and the

286 disagreement over the age of the San Angelo and Chickasha formations), Lucas (2017a) briefly

287 examined the possibility of a mass extinction between the Redtankian and Littlecrotonian LVFs

288 in the "best section" of Texas. Although he noted a peak in extinction rates during the

289 Redtankian and a decrease in genus richness during the Littlecrotonian, he was dubious over the

290 reality of a mass extinction. First, he suggested that families previously suggested to be major

291 components of the extinction, Edaphosauridae and Ophiacodontidae (Brocklehurst et al. 2013),

292 had already disappeared prior to the end of the Redtankian. Lucas also examined diversity

293 changes through the Redtankian using the specimen lists compiled by Olson $(1958,1989)$ for the

294 Arroyo, Vale and Choza formations, demonstrating that diversity was decreasing throughout the

295 Redtankian, rather than there being a single decline at the end of the LVF. 
All diversity estimates presented here support a decrease in species and genus richness

297 between the Redtankian and Littlecrotonian. The diversity estimates at finer stratigraphic scales

support the observations of Lucas (2017a): the decline occurs throughout the Redtankian from a

peak in the Arroyo formation to a trough in the Choza formation, followed by a slight, but not

substantial, recovery in the San Angelo formation. The same inferences may be made from

301

origination and extinction rates. While origination rates peak at the bottom of the Arroyo

302

formation (explaining the peak in species richness at this time), extinction rates are noticeably

303

higher in the Arroyo formation than the background rates experienced for most of the early

304

Permian. Only once prior to this are extinction rates reliably inferred to reach similar levels: at

the top of the Belle Plains Formation. The extinction rates experienced in the Choza Formation

are considerably higher than any other time in the early Permian, and origination rates do not rise

until later, at the bottom of the San Angelo formation (coinciding with the post-extinction

recovery).

Does this period of elevated extinction rates and declining diversity constitute a mass

extinction? Lucas (2017a) argued not, since it was a prolonged decline throughout the

311 Redtankian LVF. Unfortunately, there is no set definition of a "mass extinction", and while the

312 general consensus does seem to be elevated extinction over a short period of time, there is no

313 indication of how short a time that should be. Discussion of mass extinctions in the scientific

314 literature have included events where extinction rates were substantially higher than background

315 rates over periods of millions of years. For example, discussion of the late Devonian mass

316 extinction (one of the "big five" mass extinctions) has in the past suggested a duration of up to

317 three million years (Racki 2005); the end Triassic extinction (another of the big five) is thought

318 to represent periods of elevated extinction rate bracketing the entire Rhaetian stage (Ward et al. 
319 2001, 2004), a duration of almost seven million years based on the most recent timescale of the

320 International Commission on Stratigraphy. Moreover, if one is to follow the stratigraphic ages

321 espoused by Lucas (1998, 2002, 2004, 2006, 2017a,b), the Redtankian would be compressed into

322 a period covering less than four million years. During these four million years, extinction rates

323 remain consistently higher than background levels. The Arroyo Formation records a substantial

324 increase in extinction, and the Choza Formation records extinction rates that have more-than

325 doubled those of the Arroyo, higher than in any other formation. The number of tetrapod species

326 observed in the Choza Formation is less than a quarter of those observed in the Arroyo

327 Formation, and subsampling does not diminish the extent of the diversity loss.

328 It is worth noting at this point that mass extinctions appearing in the fossil record as

329 prolonged declines is an issue that has a long history of discussion in the published literature,

330 going back to the work of Signor \& Lipps (1982). The fact that the last appearance of a taxon in

331 the fossil record is not its last true appearance, combined with differential preservation

332 probabilities of different taxa, causes a set of species, which in reality died out nearly

333 simultaneously, to appear to have died out over a longer period of time (Butterfield 1995), a

334 phenomenon dubbed the Signor-Lipps effect. Lucas (2017a) acknowledged the Signor-Lipps

335 effect in his introduction but did not mention it in his discussion of specific extinction events. He

336 also employed no sampling correction when examining diversity and extinction rate, instead

337 arguing that "whatever biases exist may be roughly equivalent in the Permian tetrapod record

338 across times and localities" (Lucas 2017a, p. 35). This is simply not true: there is a wealth of

339 literature detailing analyses of the quality of the fossil record of Paleozoic tetrapods, all

340 suggesting the opposite and emphasising the need for sampling correction (Benson \& Upchurch

341 2013; Brocklehurst et al. 2013, 2014, 2017; Verriere et al. 2016). 
343 not qualify as a genuine mass extinction is that many of the clades previously deemed to have

344 died out at this time actually disappeared before the end of the Redtankian, and the number of

345 actual casualties of the event, at the family level, was very restricted. Brocklehurst et al. (2013)

346 previously noted Edaphosauridae and Ophiacodontidae as "casualties", but Lucas (2017a)

347 countered that the former's last appearance is from the Arroyo formation rather than the end of

348 the Redtankian LVF, and that the latter is not known from beyond the Mitchellcreekian LVF. In

349 the case of the Ophiacodontidae, this is actually not the case, and the family survived into the

350 Redtankian. Lucas (2017a) based his assertion on the last record of Ophiacodon, and the

351 abundant record of Varanosaurus, represented in the Arroyo Formation by the species $V$.

352 acutirostris (Broili 1904, Case 1907, 1910, Romer \& Price 1940) and V. witchitaensis (NB Pers.

353 Obs), was discounted as representing a taxon of uncertain assignment. However, almost three

354 decades of study, both anatomical and cladistic, support the ophiacodontid affinity of

355 Varanosaurus (Sumida 1989, Berman et al. 1995, Benson 2012, Brocklehurst et al. 2016), and I

356 see no reason not to count it as the youngest record of Ophiacodontidae. Regarding

357 Edaphosauridae, only one species of Edaphosaurus is known from the Arroyo formation $(E$.

358 pogonias), but it still represents one of the most abundant herbivores in this fauna (Data S1).

359 Neural spine material of Edaphosaurus is also known from the Hennessey Formation (Daly

360 1973), a Redtankian aged formation in Oklahoma. It is clear, therefore, that both

361 Ophiacodontidae and Edaphosauridae survived into the Redtankian. While they may not have

362 survived beyond the lowest of the Redtankian formations, this does not remove them from the

363 Olson's Extinction casualty list. As already discussed, extinction rates were raised considerably 
364 above background levels throughout the Redtankian, and extinctions of the taxa of the Arroyo

365 formation should be included in event.

366 Even if we are to limit our discussion to clades which went extinct at the end of the

367 Choza Formation, there are still multiple clades above the genus level which may be included in

368 the list of casualties of Olson's extinction, mostly amphibians. Probably the most prominent are

369 the Eryopidae, since they represent one of the few cases where we have data on their

370 disappearance from both palaeoequatorial (USA) and palaeotemperate localities (Brocklehurst et

371 al. 2017). Eryopids represent among the most abundant of the large amphibians throughout the

372 Cisuralian, and Eryops itself survives until the Choza Formation (Data S1). Crucially, two

373 eryopid species are known from the latest Kungurian of Russia: Clamorosaurus borealis and $C$.

374 nocturnus from the Inta formation (Gubin 1983). Eryopids are not known beyond the Kungurian

375 in either the palaeoequatorial or palaeotemperate latitiudes beyond this time (Brocklehurst et al.

376 2017). The Trimerorhachidae and Lysorophia are two more clades highly abundant throughout

377 the Cisuralian, but which do not survive beyond the Choza formation (Data S1). Both are also

378 known from the Redtankian aged Hennessey formation in Oklahoma, but not from the

379 Littlecrotonion Chickasha formation (Brocklehurst et al. 2017). The Choza Formation represents

380 the greatest peak in extinction rate in the entire Cisuralian in this particular section, both at the

381 genus and species level, with extinction rates more than double the next highest peak. Therefore,

382 even if one discounts the losses occurring earlier in the Redtankian, it is difficult to deny the

383 presence of a severe extinction event at the Redtankian/Littlecrotonian boundary.

384 There has not been much work on the environmental context surrounding this event, but

385 the extended period of extinction has been suggested to coincide with substantial climatic

386 changes recorded in the Texas sequence. The sediments of the Vale formation record a transition 
387 from an environment dominated by large perennial streams to one of braided channels, with

388 indications that flow was interrupted by substantial periods of drying (Olson 1958). The Choza

389 formation indicates a trend towards ever increasing aridity, with the uppermost deposits formed

390 almost entirely from anhydrites (Olson 1958). More work needs to be done on this crucial time

391 period, and until further research on environmental changes at this time is carried out these

392 questions cannot be answered with great certainty.

393

\section{Conclusions}

395 No matter what time-binning scheme is employed, no matter whether the data is

396 examined at the species or genus level, and no matter whether the data is corrected for sampling

397 or not, a substantial mass extinction event is observed in tetrapods during the Redtankian Land

398 Vertebrate Fanuachron. Throughout the Redtankian, extinction rates were raised substantially

399 above background levels, rising to a peak in the uppermost Choza Formation. Tetrapod diversity 400 declines throughout this period, and by the end of the Redtankian, species richness is less than a 401 quarter of that observed at the start.

402

\section{Acknowledgements}

404 I would like to thank Roger Benson and John Alroy for helpful comments. The reviewers 405 Kenneth Angielczyk and Bruce Rubidge and editor Graciela Piñeiro provided many helpful 406 suggestions that greatly improved the quality of the paper. I am also grateful to collection 407 managers who gave access to their collection catalogues and the collections themselves: Jennifer 408 Larsen (Sam Noble Oklahoma Museum of Natural History), William F. Simpson (FMNH), Dan 
409 Brinkman (Peabody Museum of Natural History), Jessica Cundiff (MCZ), Carl Mehling

410 (AMNH) and Pat Holroyd (UCMP).

411

412 References

413 Alroy J. 1998. Equilibrial diversity dynamics in North American mammals. Pp. 233-287 in M.

414 L. McKinney and J. A. Drake, eds. Biodiversity dynamics: turnover of populations, taxa 415 and communities. Columbia University Press, New York.

416 Alroy J. 2010a Geographical, environmental and intrinsic biotic controls on Phanerozoic marine 417 diversification. Palaeontology 53:1211-1235.

418 Alroy J. 2010b. Fair sampling of taxonomic richness and unbiased estimation of origination and extinction rates. The Paleontological Society Papers 16: 55-80.

Alroy J. 2014. Accurate and precise estimates of origination and extinction rates. Paleobiology

421 40:374-397.

Alroy J. 2015a A new twist on a very old binary similarity coefficient. Ecology 96:575-586

Alroy J. 2015b A more precise speciation and extinction rate estimator. Paleobiology 41: 633639

Archibald SB, Bossert WH, Greenwood DR, Farrell BD. 2010. Seasonality, the latitudinal gradient of diversity, and Eocene insects. Paleobiology 36:374-398.

Benson RB. 2012. Interrelationships of basal synapsids: cranial and postcranial morphological 428 partitions suggest different topologies. Journal of Systematic Palaeontology 10: 601-624. 
429 Benson RBJ, Upchurch P. 2013 Diversity trends in the establishment of terrestrial vertebrate 430 ecosystems: interactions between spatial and temporal sampling biases. Geology 41:4346.

432 Benton MJ. 2012. No gap in the Middle Permian record of terrestrial vertebrates. Geology 433 40:339-342.

434 Berman DS, Reisz RR, Bolt JR, Scott D. 1995. The cranial anatomy and relationships of the 435 synapsid Varanosaurus (Eupelycoauria: Ophiacodontidae) from the early Permian of Texas and Oklahoma. Annals of the Carnegie Museum 64:99-133

437

438

439

440

441

442

444

446

447 448 449

Brocklehurst N, Fröbisch J. 2014. Current and historical perspectives on the completeness of the fossil record of pelycosaurian-grade synapsids. Paleogeography, Paleoclimatology, Paleoecology 399:114-126

Brocklehurst N, Kammerer CF, Fröbisch J. 2013 The early evolution of synapsids and the influence of sampling on their fossil record. Paleobiology 39:470-490.

Brocklehurst N, Ruta M, Müller J, Fröbisch J. 2015 Elevated extinction rates as a trigger for diversification rate shifts: early amniotes as a case study. Scientific Reports 5:17104.

Brocklehurst N, Reisz RR, Fernandez V, Fröbisch J. 2016. A re-description of 'Mycterosaurus' smithae, an Early Permian eothyridid, and its impact on the phylogeny of pelycosauriangrade synapsids. PloS one, 11: e0156810.

Brocklehurst N, Day MO, Rubidge BS, Fröbisch J. 2017 Olson's extinction and the latitudinal biodiversity gradient of tetrapods in the Permian. Proceedings of the Royal Society B 284: 20170231 
450 Brocklehurst N, Day MO, Fröbisch J. 2018a. Accounting for differences in species frequency distributions when calculating beta diversity in the fossil record. Methods in Ecology and 453 Brocklehurst N, Day MO, Fröbisch J. 2018b. Data from: Accounting for differences in species frequency distributions when calculating beta diversity in the fossil record. Dryad Digital Repository. https://doi.org/10.5061/dryad.ghoq91j

Broili F. 1904. Permische Stegocephalen und Reptilien aus Texas. Palaeontographica 51:1-120

Butterfield NJ. 1995. Secular distribution of Burgess-Shale-type preservation. Lethaia 28: 1-13.

Case EC. 1907. Revision of the Pelycosauria of North America. Carnegie Institution of Washington 55: 3-176

Case EC. 1910. New or Little Known Reptiles and Amphibians from the Permian of Texas. Order of the Trustees, American Museum of Natural History.

Chao A, Jost L. 2012. Coverage-based rarefaction and extrapolation: standardising samples by completeness rather than size. Ecology 93: 2533-2547

Close R, Evers SW, Alroy J, Butler RJ. 2018. How should we estimate diversity in the fossil record? Testing richness estimators using sampling-standardised discovey curves. Methods in Ecology and Evolution In Press.

Daly E. 1973. A Lower Permian vertebrate fauna from southern Oklahoma. Journal of Paleontology 47: 562-589 Paleobiology 20:424-444. 
471 Foote 2000. Origination and extinction components of taxonomic diversity: general problems. 472 Paleobiology 26:74-102.

473 Gibert C, Escarguel G. 2017. Evaluating the accuracy of biodiversity changes through geologic 474 times: from simulation to solution. Paleobiology 43:667-692

475 Grimm EC. 1987. CONISS: a FORTRAN 77 program for stratigraphically constrained cluster 476 analysis by the method of incremental sum of squares. Computers \& geosciences 13:13477 35.

478 479

Gubin YM. 1983. The first eryopids from the Permian of the Eastern European platform.

$$
\text { Paleontologicheskii Zhurnal 4:110-115 }
$$

Hentz TF. 1988. Lithostratigraphy and paleoenvironments of upper Paleozoic continental red beds, north-central Texas: Bowie (new) and Wichita (revised) groups. The University of Texas at Austin Bureau of Economic Geology Report of Investigations 170:1-55

Hillebrand H. 2004 On the generality of the latitudinal diversity gradient. American Naturalist $163: 192-211$

Hook RW. 1989. Stratigraphic distribution of tetrapods in the Bowie and Wichita groups, PermoCarboniferous of north-central Texas. In: Hook, R.W. (Ed.), Perm-oCarboniferous Vertebrate Paleontology, Lithostratigraphy and Depositional Environments of Northcentral Texas. Society of Vertebrate Paleontology, Austin, 47-53.

Juggins, S., 2009. Rioja: an R package for the analysis of quaternary science data, Version 0.5-3.

Kemp TS. 2006 The origin and early radiation of the therapsid mammal-like reptiles: a palaeobiological hypothesis. Journal of Evolutionary Biolology 19:1231-1247. 
492 Lozovsky, V.R. 2003. Correlation of the continental Permian of norther Pangea: a review. 493 Bolletina della Societa Italiano Volume Especiale 2:239-244.

494 Lucas, S.G., 1994. Triassic tetrapod extinctions and the compiled correlation e $\square$ ect. Canadian 495 Society of Petroleum Geology Memoir 17, 869-875.

496 Lucas, S.G., 1998b. Toward a tetrapod biochronology of the Permian. New Mexico Museum of $497 \quad$ Natural History Science Bulletin 12, 71-91.

498 Lucas, S.G. 2002. The reptile Macroleter: First vertebrate evidence for correlation of Upper 499 Permian continental strata of North America and Russia: Discussion. Geological Society $500 \quad$ of America Bulletin 114:1174-1175

501 502

Lucas SG. 2004. A global hiatus in the Middle Permian tetrapod fossil record. Stratigraphy 1:4764.

Lucas SG. 2006. Global Permian tetrapod biostratigraphy and biochronology. In: Lucas, S.G., Cassinis, G., Schneider, J.W. (Eds.), Non-marine Permian Biostratigraphy and Biochronology. Geological Society London Special Publications Vol. 265, 65-93

Lucas SG. 2017a. Permian tetrapod extinction events. Earth Science Reviews 170:31-60

Lucas SG. 2017b. Permian tetrapod biochronology, correlation and evolutionary events. In: Lucas, S.G., Shen, S.Z. (Eds), The Permian Timescale. Geological Socitey of Lindon Special Publications Vol. 450, 405-444

Lucas SG, Heckert SB. 2001 A global hiatus in the record of Middle Permian tetrapods. Journal of Vertebrate Paleontology 21:75. 
512 Mannion PD, Benson RBJ, Upchurch P, Butler RJ, Carrano WT, Barrett PM. 2012 A temperate

513 palaeodiversity peak in Mesozoic dinosaurs and evidence for Late Cretaceous

514 geographical partitioning. Global Ecolology and Biogeography Letters 21:898-908.

515 Mannion PD, Upchurch P, Benson RBJ, Goswami A. 2014 The latitudinal biodiversity gradient $516 \quad$ through deep time. Trends in Ecology and Evolution 29:42-50.

517 Miller AI, and Foote M. 1996. Calibrating the Ordovician radiation of marine life: implications

518 for Phanerozoic diversity trends. Paleobiology, 22:304-309.

519 Olson, E.C., 1958. Fauna of the Vale and Choza: 14 summary, review, and integration of 520 geology and the faunas. Fieldiana. 10, 397-448.

521 Olson EC. 1962 Late Permian terrestrial vertebrates, USA and USSR. Transactions of the $522 \quad$ American Philosophical Society 52:1-224.

523 Olson EC. 1966 Community evolution and the origin of mammals. Ecology 47:291-302.

524 Olson EC. 1982 Extinctions of Permian and Triassic nonmarine vertebrates. GSA Special Papers $525 \quad 190: 501-512$.

526 Olson EC. 1989. The Arroyo Formation (Leonardian: lower Permian) and its vertebrate fossils. 527 Texas Memorial Museum Bulletin 2: 1-25

528 Plummer FB, Moore RC. 1921. Stratigraphy of the Pennsylvanian formations of northcentral $529 \quad$ Texas. University of Texas Bulletin 2132: 1-237

530 Racki G. 2005. Toward understanding Late Devonian global events: few answers, many 531 questions. Developments in Palaeontology and Stratigraphy 20: 5-36.

532 Raup DM. 1972. Taxonomic diversity during the Phanerozoic. Science 177:1065-1071. 
533 Reisz RR, Laurin M. 2001. The reptile Macroleter: First vertebrate evidence for correlation of

534 Upper Permian continental strata of North America and Russia. Geological Society of America Bulletin, 113:1229-1233.

536

537

538

539

540

541

542

543

544

545

546

547

548

549

550

551

552

553

Reisz RR, Laurin M. 2002. The reptile Macroleter: First vertebrate evidence for correlation of Upper Permian continental strata of North America and Russia: Discussion and reply. Geological Society of America Bulletin, 114:1174-1175.

Romer AS. 1928. Vertebrate faunal horizons in the Texas Permo-Carboniferous red beds. University of Texas Bulletin 2801, 67-108.

Romer AS. 1935. Early history of Texas redbeds vertebrates. Geological Society of America Bulletin 46, 1597-1658.

Romer AS. Price LI. 1940. Review of the Pelycosauria. Geological Society of America Special Papers Number 28

Rose PJ, Fox DL, Marcot J, Badgley C. 2011 Flat latitudinal gradient in Paleocene mammal richness suggests decoupling of climate and biodiversity. Geology 39:163-166.

Ruta M, Benton MJ. 2008 Calibrated diversity, tree topology and the mother of mass extinctions: the lesson of temnospondyls. Palaeontology 51:1261-1288.

Ruta M, Cisneros JC, Liebrecht T, Tsuji LA, Müller J. 2011 Amniotes through major biological crises: faunal turnover among parareptiles and the end-Permian mass extinction. Palaeontology 54:1117-1137.

Sahney S, Benton MJ. 2008 Recovery from the most profound mass extinction of all time. Proceedings of the Royal Society B 275:759-765. 
554 Sepkoski Jr. JJ. 1984. A kinetic model of Phanerozoic taxonomic diversity. III. Post Paleozoic families and mass extinctions. Paleobiology 10, 246-267.

556 Signor PW., Lipps JH. 1982. Sampling bias, gradual extinction patterns, and catastrophes in the fossil record. In L. T. Silver and P. H. Schultz (ed.) Geological implications of impacts of large asteroids and comets on the Earth. Geological Society of America Special

Sumida SS. 1989. Reinterpretation of vertebral structure in the Early Permian pelycosaur Varanosaurus acutirostris (Amniota, Synapsida). Journal of Vertebrate Paleontology 9:

562 Publication, vol. 190: 291-296.

Verrière A, Brocklehurst N, Fröbisch J. 2017. Assessing the completeness of the fossil record: comparison of different methods applied to parareptilian tetrapods (Vertebrata: Sauropsida). Paleobiology 42:680-695

Ward PD, Haggart JW, Carter ES, Wilbur D, Tipper HW, Evans T. 2001. Sudden productivity collapse associated with the Triassic-Jurassic boundary mass extinction. Science 292:.1148-1151.

Ward PD, Garrison GH, Haggart JW, Kring DA, Beattie MJ. 2004. Isotopic evidence bearing on Late Triassic extinction events, Queen Charlotte Islands, British Columbia, and implications for the duration and cause of the Triassic/Jurassic mass extinction. Earth

573 Willig MR, Kaufman DM, Stevens RD. 2003 Latitudinal gradients of biodiversity: pattern, and Planetary Science Letters 224: 589-600. process, scale, and synthesis. Annual Review of Ecology, Evolution and Systematics 34:273-309. 
576 Yasuhara M, Hunt G, Dowsett HJ, Robinson MM, Stoll DK. 2012 Latitudinal species diversity

577 gradient of marine zooplankton for the last three million years. Ecology Letters 15:1174-

$578 \quad 1179$.

579

580 Figure Captions

581 Fig. 1: The time bins used in the diversity analysis

582 Legend: A) The tetrapod bearing formations in Texas; B) the Land Vertebrate Faunachrons

583 (LVFs) redefined by CONISS; C) the original LVFs. The cluster dendrogram indicates

584 the grouping of the formations by CONISS.

585

586 Fig. 2: Taxic Diversity Estimates

587 Legend: Diversity estimates without correcting for sampling, using four different methods of

588 time-binning the data. A) Species level diversity estimate; B) Genus level diversity

$589 \quad$ estimate.

590

591 Fig 3: Subsampled diversity estimates (Original Land Vertebrate Faunachrons)

592 Legend: Numbers of species (A) and genera (B) in each land vertebrate faunachron (original

593 definitions), corrected for sampling heterogeneity using shareholder quorum

$594 \quad$ subsampling. Legend indicates quorum level. 
596 Fig 4: Subsampled diversity estimates (redefined Land Vertebrate Faunachrons)

597 Legend: Numbers of species (A) and genera (B) in each land vertebrate faunachron (definitions 598 based on CONISS), corrected for sampling heterogeneity using shareholder quorum 599 subsampling. Legend indicates quorum level.

600

601 Fig 5: Subsampled diversity estimates (Formations)

602 Legend: Numbers of species (A) and genera (B) in each formation, corrected for sampling 603 heterogeneity using shareholder quorum subsampling. Legend indicates quorum level.

604

605 Fig 6: Subsampled diversity estimates (half-million-year time bins)

606 Legend: Means of the numbers of species (A) and genera (B) found in each half-million-year 607 time bin in each of the 100 stochastic distributions of specimens, corrected for sampling 608 heterogeneity using shareholder quorum subsampling. Legend indicates quorum level.

609

610 Fig 7: Extinction Rates

611 Legend: Median (thick black lines) of the extinction rates calculated for each half-million-year 612 time bin in each of the 100 stochastic distributions of specimens at the genus (A) and

613 species (B) levels. Dashed lines indicate standard error around the median.

614

615 Fig 8: Origination Rates 
616 Legend: Median (thick black lines) of the origination rates calculated for each half-million-year

617 time bin in each of the 100 stochastic distributions of specimens at the genus (A) and

618 species (B) levels. Dashed lines indicate standard error around the median.

619

620

621 


\section{Figure 1}

The time bins used in the diversity analysis
A) The cluster dendrogram indicating the grouping of the formations by CONISS; B) The tetrapod bearing formations in Texas; C) the Land Vertebrate Faunachrons (LVFs) redefined by CONISS; D) the original LVFs. 


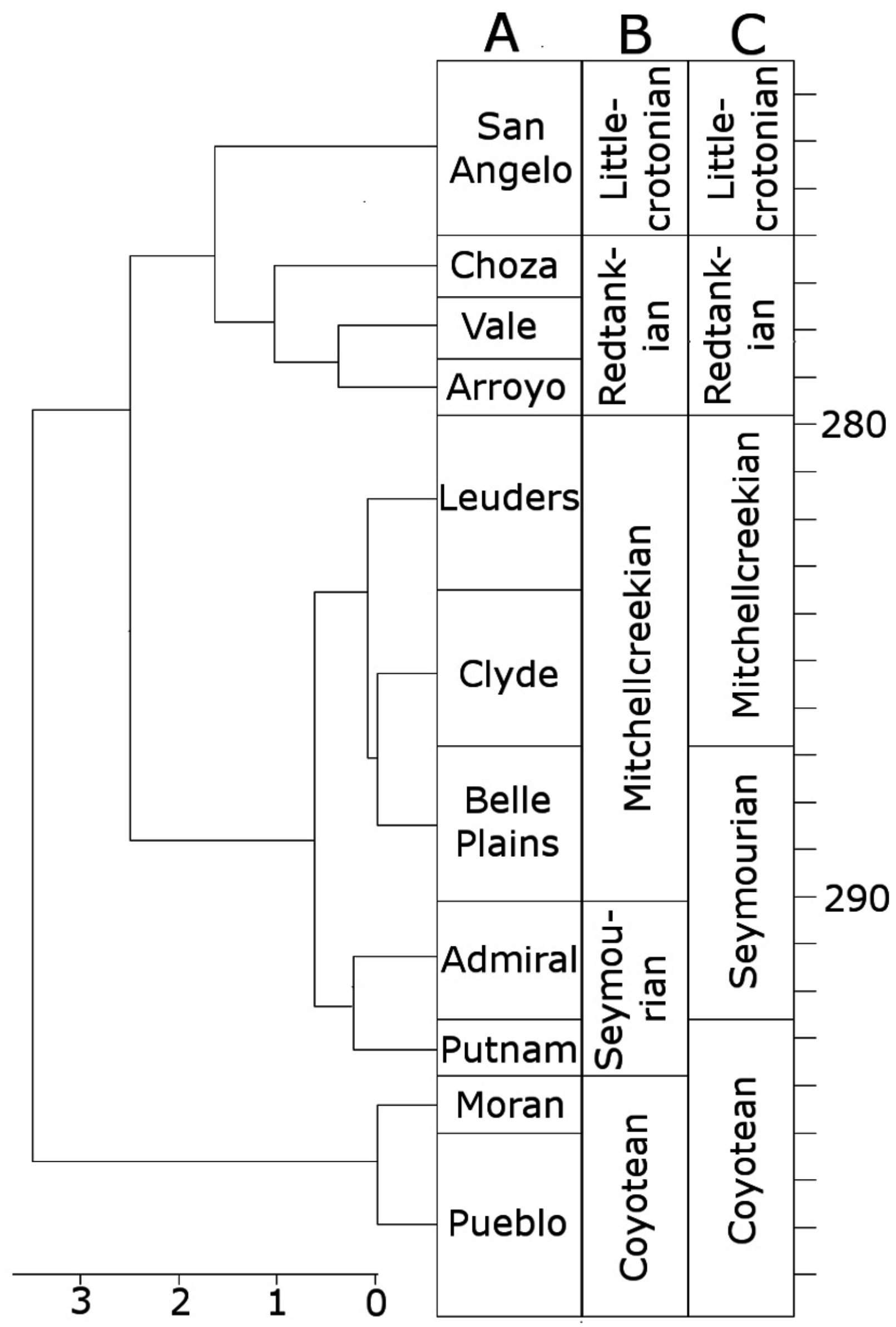


Figure 2

Taxic diversity estimates

Diversity estimates without correcting for sampling, using four different methods of time-binning the data. A) Species level diversity estimate; B) Genus level diversity estimate.

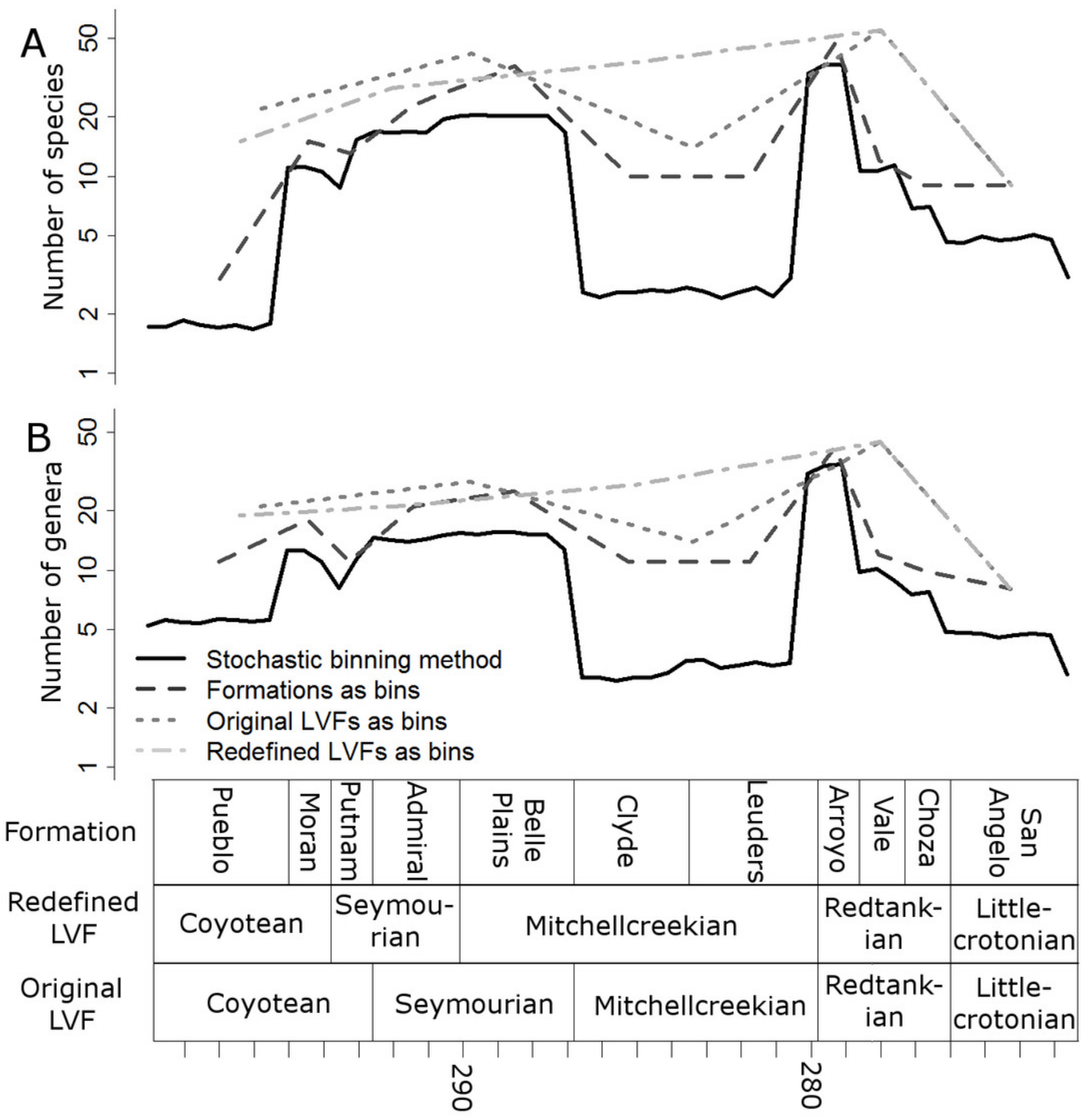




\section{Figure 3}

Subsampled diversity estimates (Original Land Vertebrate Faunachrons)

Numbers of species (A) and genera (B) in each land vertebrate faunachron (original

definitions), corrected for sampling heterogeneity using shareholder quorum subsampling.

Legend indicates quorum level. 


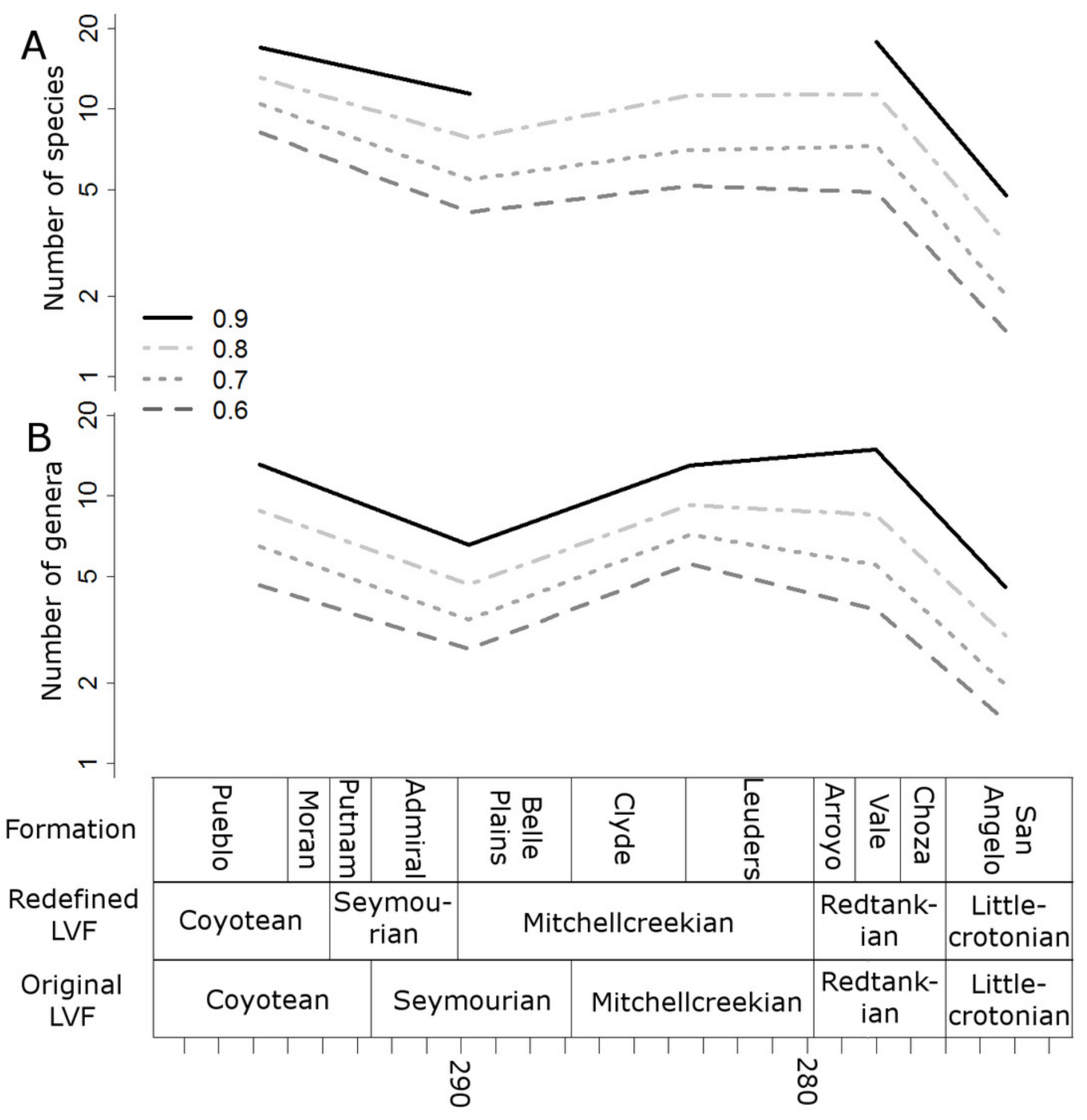




\section{Figure 4}

Subsampled diversity estimates (redefined Land Vertebrate Faunachrons)

Numbers of species (A) and genera (B) in each land vertebrate faunachron (definitions based on CONISS), corrected for sampling heterogeneity using shareholder quorum subsampling. Legend indicates quorum level. 


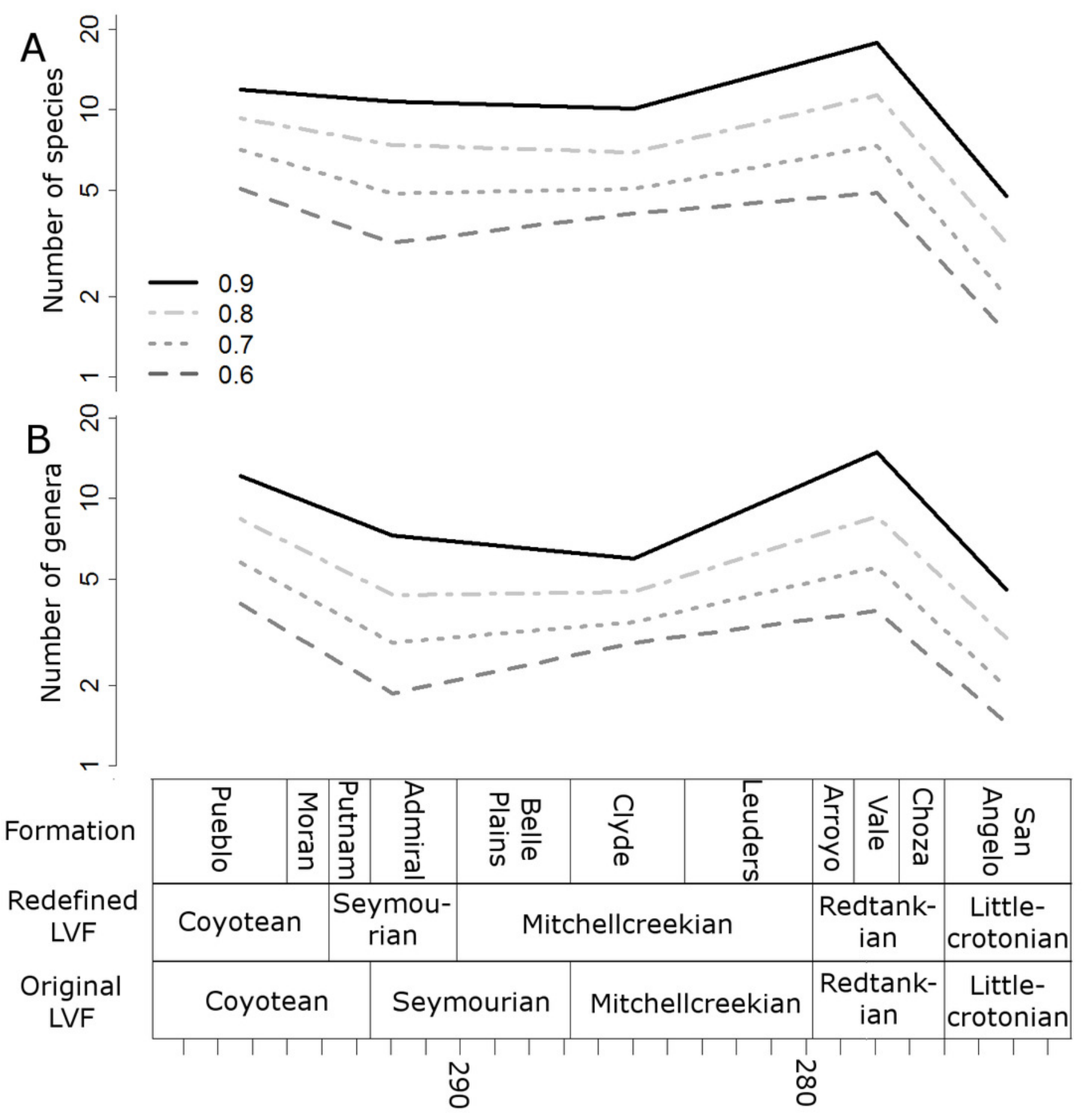


Figure 5

Subsampled diversity estimates (formations)

Numbers of species (A) and genera (B) in each formation, corrected for sampling heterogeneity using shareholder quorum subsampling. Legend indicates quorum level.

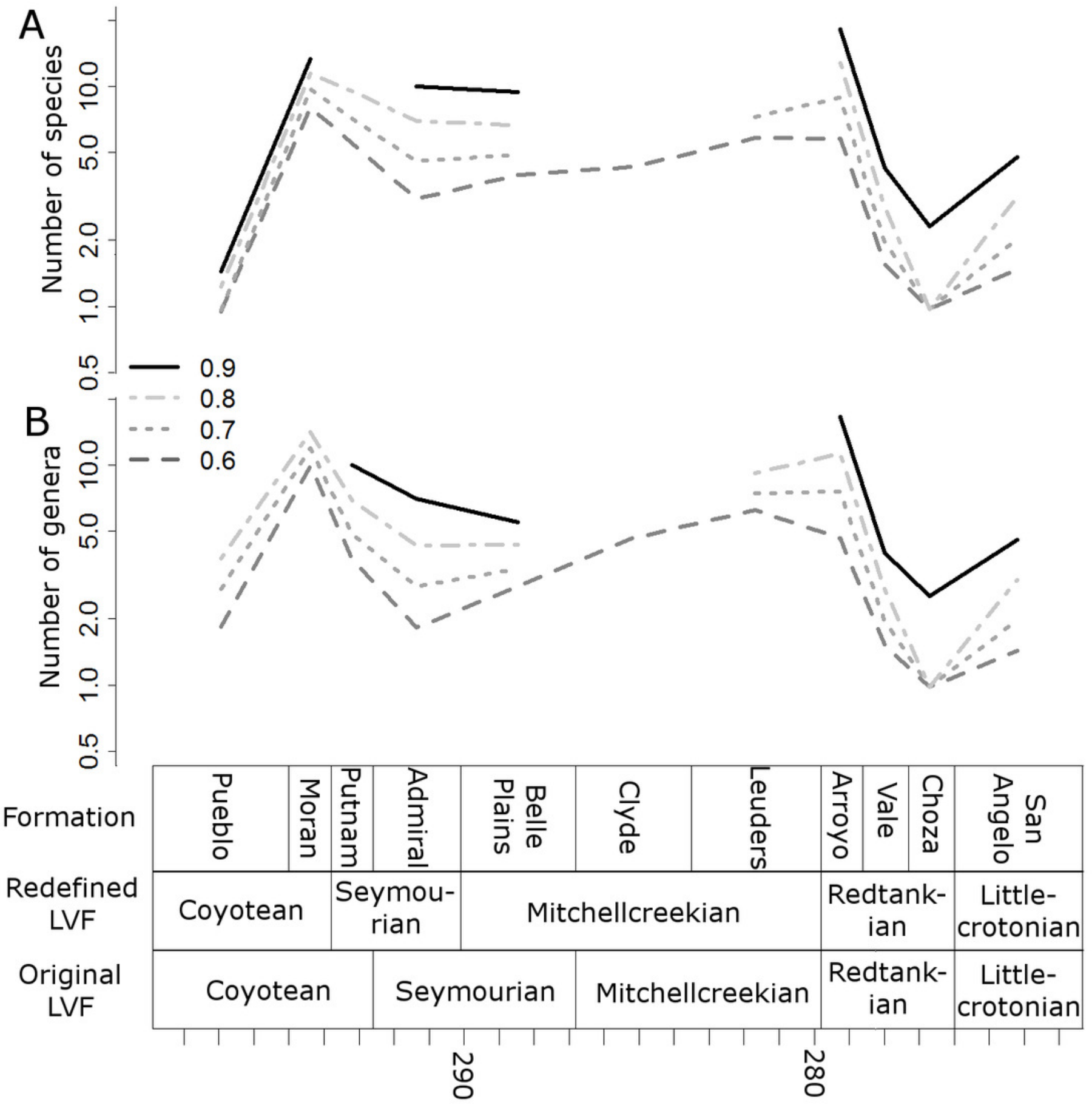


Figure 6

Subsampled diversity estimates (half-million-year time bins)

Means of the numbers of species (A) and genera (B) found in each half-million-year time bin in each of the 100 stochastic distributions of specimens, corrected for sampling heterogeneity using shareholder quorum subsampling. Legend indicates quorum level.
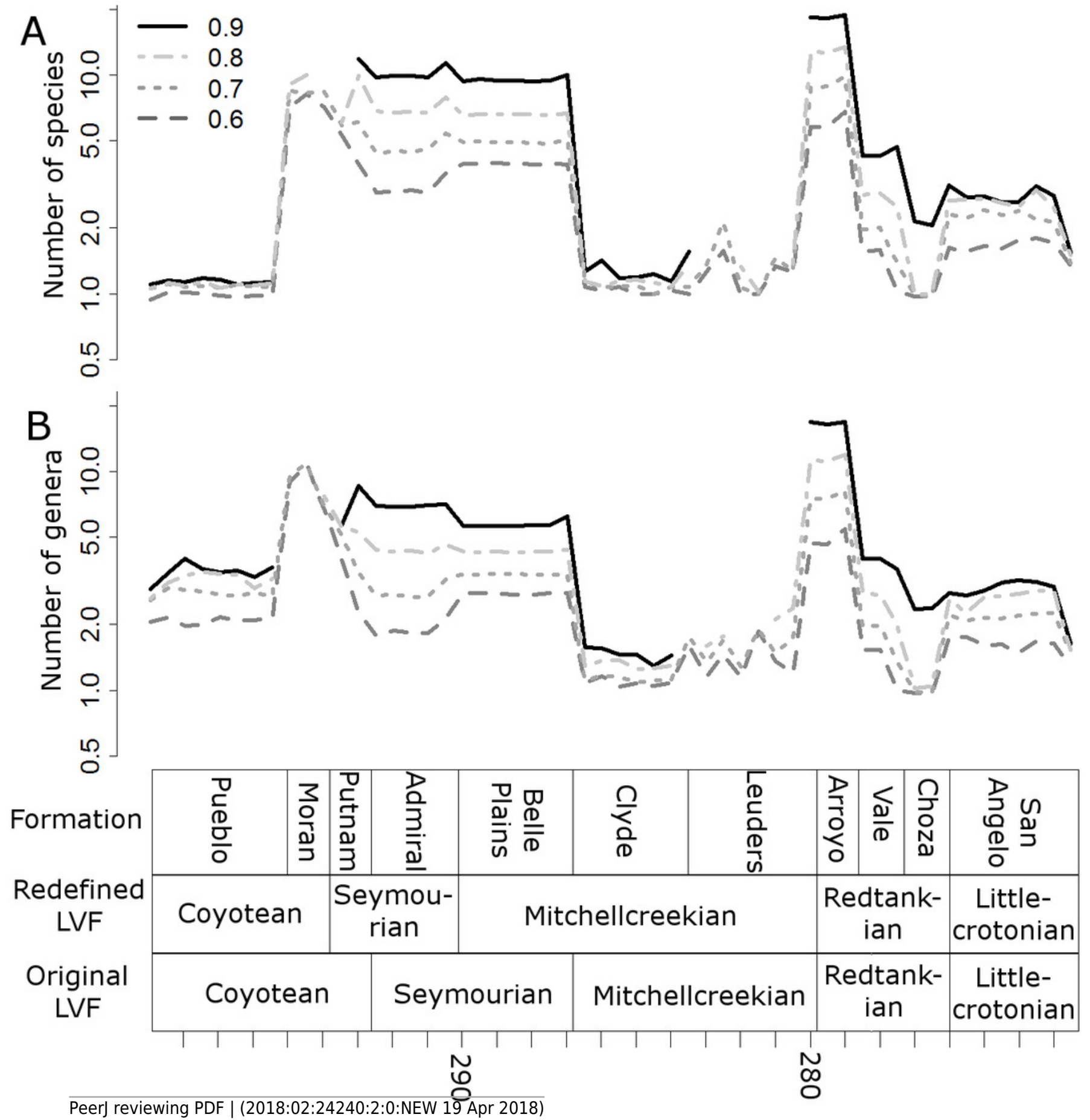


\section{Figure 7}

\section{Extinction rates}

Median (thick black lines) of the extinction rates calculated for each half-million-year time bin in each of the 100 stochastic distributions of specimens at the genus (A) and species (B) levels. Dashed lines indicate standard error around the median. 


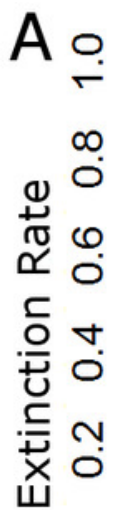

ำ
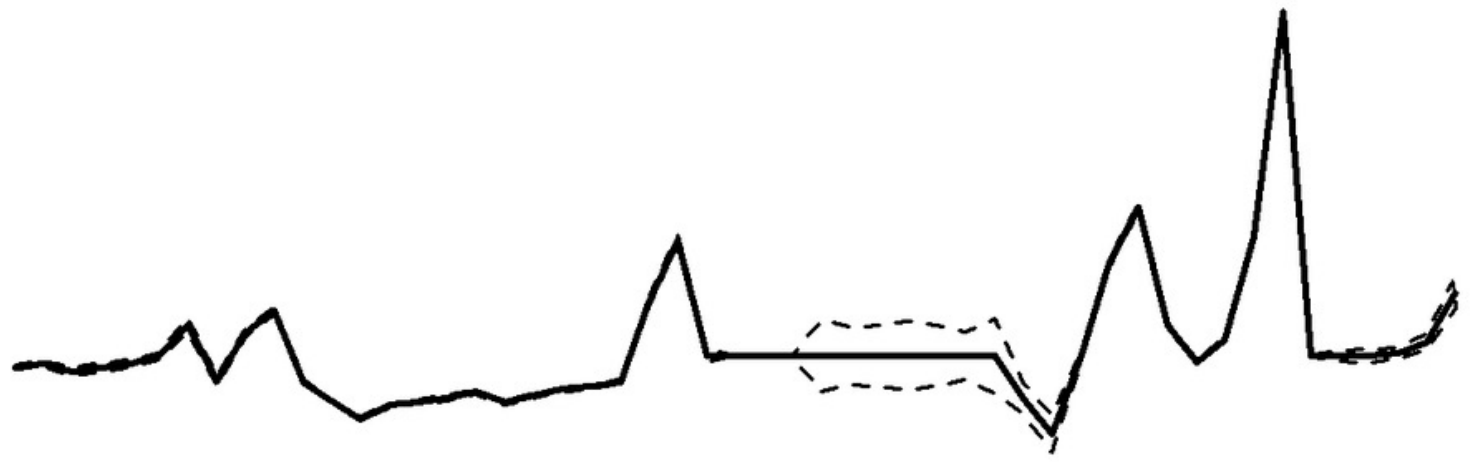

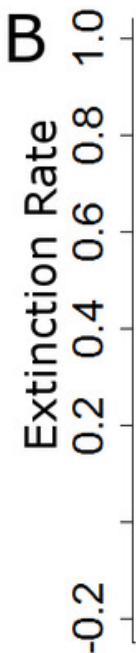
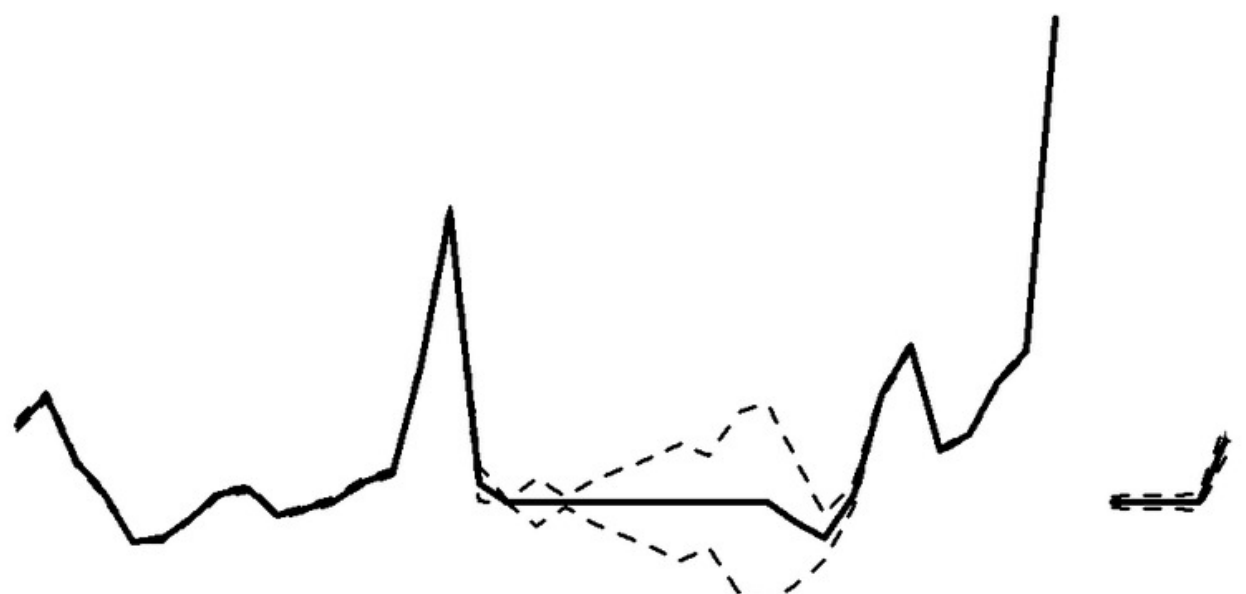

Formation

\begin{tabular}{|c|c|c|c|c|c|c|c|c|c|c|}
\hline $\begin{array}{l}\text { D } \\
\frac{D}{D} \\
\text { 믕 }\end{array}$ & $\begin{array}{l}\frac{3}{0} \\
\frac{0}{3}\end{array}$ & 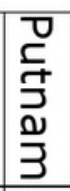 & $\begin{array}{l}\frac{1}{2} \\
\frac{2}{3} . \\
\underline{\underline{0}}\end{array}$ & 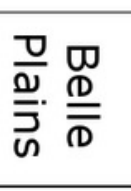 & $\frac{\Omega}{\grave{\alpha}}$ & $\begin{array}{l}\frac{1}{D} \\
\frac{1}{0} \\
\frac{0}{D} \\
\end{array}$ & $\begin{array}{l}\text { D } \\
\text { 궁 } \\
\text { Ò } \\
\end{array}$ & $\frac{\widehat{\Phi}}{\Phi}$ & $\begin{array}{l}\mathcal{O} \\
\mathcal{N} \\
\mathcal{N}\end{array}$ & 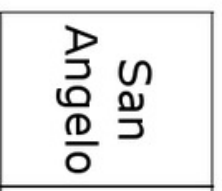 \\
\hline \multicolumn{2}{|c|}{ Coyotean } & \multicolumn{2}{|c|}{$\begin{array}{c}\text { Seymou- } \\
\text { rian }\end{array}$} & \multicolumn{3}{|c|}{ Mitchellcreekian } & \multicolumn{3}{|c|}{$\begin{array}{l}\text { Redtank- } \\
\text { ian }\end{array}$} & $\begin{array}{c}\text { Little- } \\
\text { crotonian }\end{array}$ \\
\hline \multicolumn{3}{|c|}{ Coyotean } & \multicolumn{2}{|c|}{ Seymourian } & \multicolumn{2}{|c|}{ Mitchellcreekian } & \multicolumn{3}{|c|}{$\begin{array}{l}\text { Redtank- } \\
\text { ian }\end{array}$} & $\begin{array}{c}\text { Little- } \\
\text { crotonian }\end{array}$ \\
\hline 11 & T & & & & & & & $T$ & $T$ & \begin{tabular}{l|l|l} 
& 1 & 1
\end{tabular} \\
\hline
\end{tabular}


Figure 8

Origination rates

Median (thick black lines) of the origination rates calculated for each half-million-year time bin in each of the 100 stochastic distributions of specimens at the genus (A) and species (B) levels. Dashed lines indicate standard error around the median. 


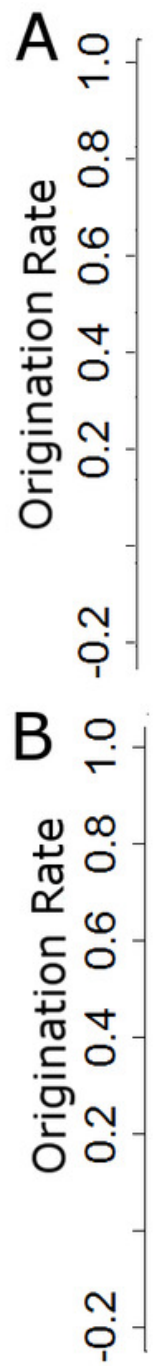

\begin{tabular}{|c|c|c|c|c|c|c|c|c|c|c|c|}
\hline Formation & $\begin{array}{l}\overline{0} \\
\frac{D}{D} \\
\frac{0}{0} \\
\end{array}$ & 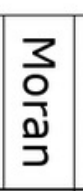 & 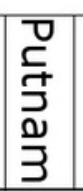 & 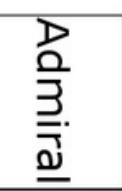 & $\frac{\frac{D}{N}}{\frac{D}{二}} \frac{\mathbb{D}}{\bar{D}}$ & $\underset{\frac{O}{\alpha}}{\stackrel{O}{d}}$ & $\begin{array}{l}\frac{1}{D} \\
\frac{1}{2} \\
\frac{D}{D} \\
\frac{1}{n}\end{array}$ & 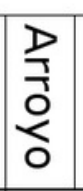 & $\frac{\nwarrow}{\Phi}$ & 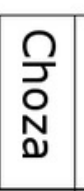 & $\begin{array}{l}\stackrel{D}{J} \text { U } \\
\stackrel{0}{\mathbb{D}} \\
\frac{D}{O}\end{array}$ \\
\hline $\begin{array}{l}\text { Redefined } \\
\text { LVF }\end{array}$ & \multicolumn{2}{|c|}{ Coyotean } & Se) & $\begin{array}{l}\text { mou- } \\
\text { ian }\end{array}$ & \multicolumn{3}{|c|}{ Mitchellcreekian } & \multicolumn{3}{|c|}{$\begin{array}{l}\text { Redtank- } \\
\quad \text { ian }\end{array}$} & $\begin{array}{c}\text { Little- } \\
\text { crotonian }\end{array}$ \\
\hline $\begin{array}{l}\text { Original } \\
\text { LVF }\end{array}$ & \multicolumn{3}{|c|}{ Coyotean } & \multicolumn{2}{|c|}{ Seymourian } & \multicolumn{2}{|c|}{ Mitchellcreekian } & \multicolumn{3}{|c|}{$\begin{array}{c}\text { Redtank- } \\
\text { ian }\end{array}$} & $\begin{array}{c}\text { Little- } \\
\text { crotonian }\end{array}$ \\
\hline & 11 & 11 & 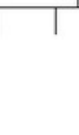 & 11 & & & $\begin{array}{lll} & 1\end{array}$ & & $T$ & 1 & \\
\hline
\end{tabular}

